\title{
Physiological effects of two driving pressure-based methods to set positive end-expiratory pressure during one lung ventilation
}

\author{
Savino Spadaro ${ }^{1}$ (i) - Salvatore Grasso ${ }^{2} \cdot$ Dan Stieper Karbing $^{3} \cdot$ Giuseppe Santoro $^{1} \cdot$ Giorgio Cavallesco $^{4}$. \\ Pio Maniscalco ${ }^{4}$. Francesca Murgolo ${ }^{2} \cdot$ Rosa Di Mussi ${ }^{2} \cdot$ Riccardo Ragazzi $^{1}$ - Stephen Edward Rees ${ }^{3}$. \\ Carlo Alberto Volta ${ }^{1} \cdot$ Alberto Fogagnolo $^{1}$
}

Received: 27 May 2020 / Accepted: 17 August 2020 / Published online: 20 August 2020

(c) Springer Nature B.V. 2020

\begin{abstract}
During one-lung ventilation (OLV), titrating the positive end-expiratory pressure (PEEP) to target a low driving pressure $(\Delta \mathrm{P})$ could reduce postoperative pulmonary complications. However, it is unclear how to conduct PEEP titration: by

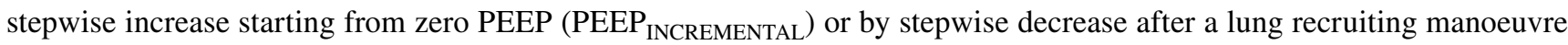
$\left(\mathrm{PEEP}_{\text {DECREMENTAL }}\right)$. In this randomized trial, we compared the physiological effects of these two PEEP titration strategies on respiratory mechanics, ventilation/perfusion mismatch and gas exchange. Patients undergoing video-assisted thoracoscopic

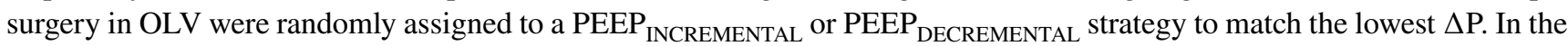
PEEP $_{\text {INCREMENTAL }}$ group, PEEP was stepwise titrated from ZEEP up to $16 \mathrm{~cm} \mathrm{H}_{2} \mathrm{O}$, whereas in the PEEP DECREMENTAL $_{\text {group }}$ PEEP was decrementally titrated, starting from $16 \mathrm{~cm} \mathrm{H}_{2} \mathrm{O}$, immediately after a lung recruiting manoeuvre. Respiratory mechanics, ventilation/perfusion mismatch and blood gas analyses were recorded at baseline, after PEEP titration and at the end of surgery. Sixty patients were included in the study. After PEEP titration, shunt decreased similarly in both groups, from 50 [39-55]\% to 35 [28-42]\% in the PEEP INCREMENTAL and from 45 [37-58]\% to 33 [25-45]\% in the PEEP DECREMENTAL $_{\text {group }}$ (both $\mathrm{p}<0.001$ vs baseline). The resulting $\triangle \mathrm{P}$, however, was lower in the PEEP DECREMENTAL $_{\text {than }}$ in the PEEP INCREMENTAL group (8 [7-11] vs 10 [9-11] $\mathrm{cm} \mathrm{H}_{2} \mathrm{O} ; \mathrm{p}=0.03$ ). In the $\mathrm{PEEP}_{\text {DECREMENTAL }}$ group the $\mathrm{PaO}_{2} / \mathrm{FIO}_{2}$ ratio increased significantly after intervention (from 140 [99-176] to 186 [152-243], $\mathrm{p}<0.001$ ). Both the PEEP INCREMENTAL $_{\text {and }}$ the PEEP DECREMENTAL $_{\text {. }}$

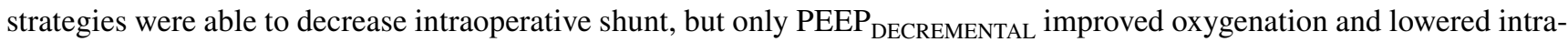
operative $\Delta \mathrm{P}$.
\end{abstract}

Clinical trial number NCT03635281; August 2018; "retrospectively registered"

Keywords Positive end-expiratory pressure $\cdot$ One-lung ventilation $\cdot$ Shunt $\cdot$ Driving pressure $\cdot$ Oxygenation

\section{Introduction}

Spadaro Savino and Grasso Salvatore have contributed equally to this work.

Electronic supplementary material The online version of this article (https://doi.org/10.1007/s10877-020-00582-z) contains supplementary material, which is available to authorized users.

Savino Spadaro

savinospadaro@gmail.com

1 Department of Morphology, Experimental Medicine and Surgery, Section of Anaesthesia and Intensive Care, Azienda Ospedaliera-Universitaria Sant' Anna, University of Ferrara, Via Aldo Moro, 8, 44124 Ferrara, Italy

2 Department of Emergency and Organ Transplant (DETO), "Aldo Moro" University of Bari, Bari, Italy
During thoracic surgery with one lung ventilation (OLV), application of positive end-expiratory pressure (PEEP) improves gas exchange and lung mechanics [1-6]. However, the approach to PEEP titration remains controversial.

3 Respiratory and Critical Care Group, Department of Health Science and Technology, Aalborg University, Aalborg, Denmark

4 Department of Morphology, Experimental Medicine and Surgery, Thoracic Surgery, Azienda Ospedaliera-Universitaria Sant' Anna, University of Ferrara, Ferrara, Italy 
Recently, we documented the highly variable impact of different PEEP levels on alveolar recruitment and gas exchange [2]; our results confirmed the expert's opinions which suggest to personalize PEEP level to balance alveolar recruitment and hyperinflation [3]. Recently, PEEP titration to the "lowest" driving pressure $(\Delta \mathrm{P})$, i.e. the difference between inspiratory plateau pressure and total PEEP, has gained a central role in the scientific debate [3-6]. Park et al. found a lower rate of postoperative pulmonary complications (PPC) in patients submitted to an incremental PEEP titration to the lowest $\Delta \mathrm{P}$ [4]. Conversely, other studies suggest an open lung approach based on a decremental PEEP trial subsequent a lung recruitment manoeuvre (LRM) [7-10].

To our knowledge, physiological trials comparing the incremental versus the decremental $\triangle \mathrm{P}$-oriented PEEP titration during OLV are lacking.

In this study, we randomly assigned patients scheduled for video-assisted thoracic surgery in OLV to an incremental PEEP (PEEP INCREMENTAL $_{\text {) versus an open lung approach }}$ with decremental PEEP titration ( PEEP $\left._{\text {DECREMENTAL }}\right)$. Our hypothesis was that the PEEP DECREMENTAL $_{\text {approach would }}$ result in more improvement in the respiratory mechanics, ventilation/perfusion mismatch and gas exchange compared to the PEEP INCREMENTAL $_{\text {technique. }}$

\section{Methods}

The trial was approved by the Ethics Committee of our institution (protocol N.11072017) and written informed consent was obtained from each patient before surgery. The trial was registered in Clinicaltrial.gov (NCT03635281). The study was performed in the Department of Anaesthesia and Intensive Care at the University Hospital of Ferrara (Italy) from August 2017 to October 2018. Results are reported according to the Consolidated Standards of Reporting Trials (CONSORT) checklist for randomized trials. The CONSORT Checklist is reported in Supplement file 1.

\subsection{Population}

We screened all patients scheduled for video-assisted thoracoscopic surgery (i.e. lobectomy or wedge resection) requiring lateral position and OLV for at least $2 \mathrm{~h}$. Exclusion criteria were: ASA (American Society of Anesthesiologists Physical Status Classification) score $\geq 4$, severe chronic respiratory failure (chronic obstructive pulmonary disease patients with Global Initiative for Chronic Obstructive Lung Disease stage 3 or 4), preoperative haemoglobin less than $10 \mathrm{~g} \mathrm{dl}^{-1}$, hemodynamic instability during LRM defined as a decrease in systolic arterial pressure of more than $20 \%$ from baseline, and unplanned thoracotomy conversion.
The day before the procedure, all patients underwent spirometry in sitting position according to the American Thoracic Society's standards (SpiroPro; Jaeger, Germany). Spirometry measurements included vital capacity, forced expiratory volume in the 1 st second $\left(\mathrm{FEV}_{1}\right)$, forced vital capacity (FVC), expiratory reserve volume (ERV), and transfer coefficient (KCO).

\subsection{Anesthesia}

Anaesthesia was induced with propofol (1.5 to $\left.2 \mathrm{mg} \mathrm{kg}^{-1}\right)$, fentanyl $\left(3 \mu \mathrm{g} \mathrm{kg}^{-1}\right)$, and rocuronium $\left(0.6 \mathrm{mg} \mathrm{kg}^{-1}\right)$. Target-controlled propofol infusion was performed with estimated effect-site concentration of $2-4 \mu \mathrm{g} \mathrm{ml}^{-1}$, targeting a bispectral index (Aspect A-2000; Aspect Medical System, USA) of 40-60. Neuromuscular blockade was provided with continuous infusion of rocuronium based on train-of-four neuromuscular monitoring. All patients were breathing $80 \%$ oxygen during induction of general anaesthesia. The trachea was intubated with an appropriately sized double lumen tube whose correct positioning was bronchoscopy confirmed. Ultrasound-guided thoracic paravertebral blocks were performed in lateral decubitus with two injections of $8 \mathrm{ml}$ Ropivacaine $0.75 \%$ [11]. Appropriate spread of local anaesthetic was confirmed with the movement of the pleura. Patients were ventilated in volume-controlled mode with constant flow using a Dräger Perseus ventilator (Drägerwerk AG and Co. KGaA, Germany). During two-lung (bilateral) ventilation, TV was set to $7 \mathrm{ml} \mathrm{kg}^{-1}$ predicted body weight (PBW) and PEEP was set to zero. These settings were maintained for approximately $10 \mathrm{~min}$ before shifting to OLV. When OLV started, TV was reduced to $5 \mathrm{ml} \mathrm{kg}^{-1}$ (PBW) and PEEP was initially maintained unchanged. PEEP was then adjusted according to the study group (see below). PEEP was applied according to the study group (see below). $\mathrm{FiO}_{2}$ was set to maintain peripheral oxygen saturation $\left(\mathrm{SpO}_{2}\right)$ equal to or greater than $92 \%$ while respiratory rate was adjusted to keep arterial $\mathrm{PaCO}_{2}$ between 40 and $60 \mathrm{mmHg}$.

\subsection{Randomization and study intervention}

After inclusion in the study, patients were randomized to the PEEP $_{\text {INCREMENTAL }}$ or a PEEP DECREMENTAL $_{\text {protocol. Rand- }}$ omization was performed 1:1 using randomization in block sizes of 2 and 4 . The time-course of the study is summarized in Fig. 1.

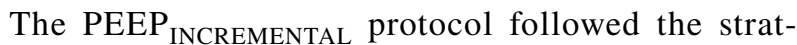
egy proposed by Park and coworkers [4]; whereas the PEEP $_{\text {DECREMENTAL }}$ protocol followed the strategy proposed by the ongoing "protective ventilation with high versus low positive end-expiratory pressure during one-lung ventilation for thoracic surgery" (PROTHOR) trial [12]. 

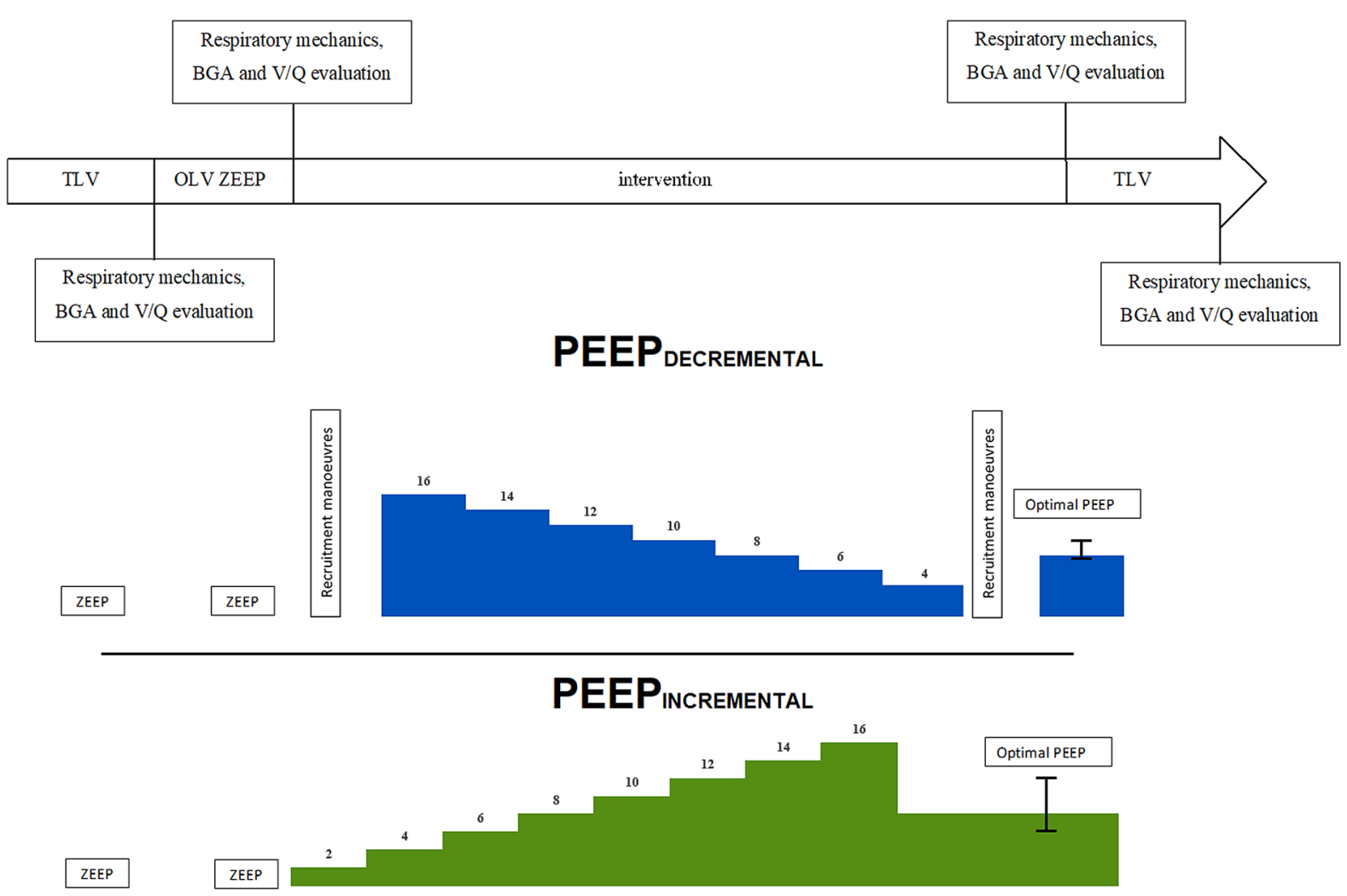

Fig. 1 Resume of study protocol

In the PEEP INCREMENTAL $_{\text {group, PEEP was increased step- }}$ wise by $2 \mathrm{~cm} \mathrm{H}_{2} \mathrm{O}$ steps, from ZEEP up to $16 \mathrm{~cm} \mathrm{H}_{2} \mathrm{O}$, while maintaining TV and RR constant. Each PEEP level was kept for 1 min before measuring $\triangle \mathrm{P}$. At the end of the PEEP titration trial, the "best" PEEP defined as the level associated with lowest $\Delta \mathrm{P}$, was set and maintained until extubation. (see Supplement File 1 for details).

Patients in PEEP DECREMENTAL $_{\text {group were submitted to a }}$ LRM immediately followed by a decremental PEEP trial. As part of the LRM, respiratory rate was set to $6 \mathrm{~min}^{-1}$ with an inspiratory-expiratory ratio of $1: 1$. TV was then increased in steps of $2 \mathrm{~mL} \mathrm{~kg}^{-1}$ PBW until reaching a target plateau pressure of $30 \mathrm{~cm} \mathrm{H}_{2} \mathrm{O}$. The step increase in TV was performed over a period of 20-30 s. Three breaths were allowed at the target plateau pressure (see Supplement File 2 for details). After performing the LRM, TV and respiratory rate were returned to the starting values, while PEEP was set to $16 \mathrm{~cm} \mathrm{H}_{2} \mathrm{O}$. Then PEEP was decreased in steps of $2 \mathrm{~cm} \mathrm{H}_{2} \mathrm{O}$, down to $4 \mathrm{~cm}$ $\mathrm{H}_{2} \mathrm{O}$, in order to identify the "best" (i.e. the lowest) $\Delta \mathrm{P}$. Each level of PEEP was maintained for $1 \mathrm{~min}$ before measuring $\Delta \mathrm{P}$.
Subsequently, another LRM, analogous to the first one, was performed and PEEP was set to the "best" PEEP level identified during the decremental PEEP trial and maintained until extubation. Safety-endpoints for interruption of the LRM were $\mathrm{a} \pm 20 \%$ variation in heart rate or a decrease of more than $20 \%$ of mean arterial pressure [13].

\subsection{Lung mechanics and ventilation/perfusion assessment}

Respiratory mechanics were assessed by the constant $\mathrm{V}^{\prime} /$ rapid occlusion method previously described in details [2]. The end-inspiratory plateau pressure was measured as the airway pressure (Paw) at the end of an end-inspiratory occlusion performed by increasing end-inspiratory pause to $40 \%$ of the inspiratory time. Driving pressure $(\Delta \mathrm{P})$ was calculated as plateau pressure-PEEP; static respiratory system compliance was calculated as TV/(end-inspiratory plateau pressure-PEEP). Mechanical power $(\mathrm{J} / \mathrm{min})$ at each time-point was calculated as described by Gattinoni et al. with the following formula [14]: 
Power $=R R *\left\{\Delta V^{2} *\left[\frac{1}{2} * E L r s+R R * \frac{(1+I: E)}{60 * I: E} *\right.\right.$ Raw $\left.]+\Delta V^{2} * P E E P\right\}$

where $\mathrm{RR}$ is respiratory rate, $\Delta \mathrm{V}$ is tidal volume, ELrs is respiratory system elastance and Raw is airway resistance $[14,15]$.

Total energy load $(\mathrm{J})$ was calculated as the product of power and ventilation time.

Shunt and V/Q matching were assessed by the Beacon Caresystem (Mermaid Care A/S, Denmark) in two-lung ventilation (TLV), OLV before intervention, OLV after intervention and in TLV at the end of the surgery. Briefly, to assess V/Q matching, the automatic lung parameter estimator (ALPE) approach $[16,17]$ used in the Beacon Caresystem, requires modification of $\mathrm{FIO}_{2}$ in three or four steps in a process taking 5-10 min. At each $\mathrm{FIO}_{2}$ level, steady state is identified and measurements are automatically taken of ventilation, $\mathrm{SpO}_{2}, \mathrm{O}_{2}$ consumption, $\mathrm{CO}_{2}$ production, and inspiratory and expiratory fractions of $\mathrm{O}_{2}$ and $\mathrm{CO}_{2}$. Oxygenation at the various $\mathrm{FIO}_{2}$ levels are used to estimate shunt and low V/Q mismatch whereas end-tidal to arterial $\mathrm{CO}_{2}$ gradient is used to calculate high V/Q mismatch. Low V/Q mismatch is reported as the $\mathrm{O}_{2}$ partial pressure difference between alveolar air and lung capillary blood prior to mixing with shunted venous blood, thus quantifying the primary effect of low V/Q on $\mathrm{O}_{2}$ exchange. High V/Q mismatch is reported as the $\mathrm{CO}_{2}$ partial pressure difference between alveolar air and lung capillary blood prior to mixing with shunted venous blood quantifying the primary effect of high $\mathrm{V} / \mathrm{Q}$ on $\mathrm{CO}_{2}$ exchange. The ALPE approach has been validated and applied in varied patient populations [1, 18-20] including patients undergoing OLV [2].

\subsection{Statistical analysis}

All analyses were pre-planned, unless specified as post-hoc. Normal distribution was tested by the Shapiro-Wilk normality test. Data are reported as mean \pm SD or median [interquartile range] as appropriate. Differences between measurements were analysed using repeated measures ANOVA or Friedman's rank analysis for data with normal or not normal distribution, respectively. When multiple comparisons were made, $\mathrm{p}$-values were adjusted by the Bonferroni post hoc procedure. Two-tailed statistical hypothesis testing was performed with a $p$ value of $\leq 0.05$ considered statistically significant. Statistical analysis was performed using SPSS Statistics for Windows, version 20.0 (IBM, USA).

Several post-hoc analyses were performed. Firstly, we investigated whether the effect of PEEP INCREMENTAL $_{\text {and }}$ PEEP $_{\text {DECREMENTAL }}$ strategies on the $\Delta \mathrm{P}$ and $\mathrm{PaO}_{2} / \mathrm{FIO}_{2}$ could be influenced by baseline $\Delta \mathrm{P}$ values. To perform this analysis, we divided the population according to a baseline $\Delta \mathrm{P}$, either $\leq 14 \mathrm{~cm} \mathrm{H}_{2} \mathrm{O}$ or $>14 \mathrm{~cm} \mathrm{H}_{2} \mathrm{O}$; this cut-off was derived from previous studies performed both in critically ill patients [21] and in one lung ventilation [2]. Furthermore, we investigated whether baseline comorbidities of the patients could influence the response to the two ventilation strategies. With this purpose, we analysed patients stratified for age, body mass index (BMI) or history of COPD.

\subsection{Sample size}

The sample size was based on the impact of PEEP titration on the shunt fraction (compared to OLV at ZEEP). Based on previous data, we assumed a decrease in shunt of at least $7 \%$ in the PEEP ${ }_{\text {DECREMENTAL }}$ group [22] and at of least $2 \%$ in PEEP INCREMENTAL $_{\text {group [2], with a } 6 \% \text { pooled standard }}$ deviation. According to this analysis, including 31 patients in each group was deemed enough to demonstrate a significant difference between the two groups, with an $90 \%$ power and a 5\% alfa error. Assuming a 5\% loss to follow up, for example for unplanned conversion to thoracotomy surgery or intraoperative hemodynamic instability, we planned to enrol 65 patients.

\section{Results}

\subsection{Population}

During the study period, 66 patients were screened for eligibility. Of those, 63 met the inclusion criteria and were included in the study; three (3) patients underwent unplanned thoracotomy conversion, leaving 60 patients for final analysis. There were no missing data or protocol deviation during the study. None of the patients analysed were excluded due to intraoperative hemodynamic instability. Preoperative clinical and demographical characteristics of the patients are presented in Table 1. The flowchart of the study is shown in Figure S1.

\subsection{V/Q mismatch}

After anaesthesia induction, shunt was 25 [19-33] \% in TLV and increased to 47 [39-56] \% $(\mathrm{p}<0.001)$ when patients were posed in lateral decubitus and ventilated in OLV at ZEEP. After PEEP titration, shunt decreased similarly in both groups (Table 2, Fig. 2), from 50 [39-55]\% to 35 [28-42]\% in the PEEP INCREMENTAL $_{\text {group (mean difference }}$ 20 [95\% CI 16-25]\%; $\mathrm{p}<0.001$ vs baseline) and from 45 
Table 1 Characteristic's patients

\begin{tabular}{|c|c|c|c|c|}
\hline Variable & $\begin{array}{l}\text { All patients } \\
n=60\end{array}$ & $\begin{array}{l}\text { PEEP }_{\text {INCREMENTAL }} \\
\mathrm{n}=30\end{array}$ & $\begin{array}{l}\text { PEEP }_{\text {DECREMENTAL }} \\
\mathrm{n}=30\end{array}$ & $\mathrm{p}$ value \\
\hline Age & $68 \pm 9$ & $66 \pm 8$ & $67 \pm 9$ & 0.571 \\
\hline BMI & $27.5 \pm 5.5$ & $27.0 \pm 6.2$ & $27.8 \pm 5.5$ & 0.576 \\
\hline ASA score & & & & 0.506 \\
\hline II & 11 & 4 & 7 & \\
\hline III & 49 & 26 & 23 & \\
\hline $\operatorname{Sex}(M / F), n$ & $40 / 20$ & $18 / 12$ & $22 / 8$ & 0.411 \\
\hline Surgery side (L/R) & $29 / 31$ & $13 / 17$ & $15 / 15$ & 0.312 \\
\hline Type of surgery & & & & 0.061 \\
\hline Lobectomy & 55 & 30 & 25 & \\
\hline Wedge resection & 5 & - & 5 & \\
\hline Duration of MV (min) & 212 [175-255] & 218 [195-255] & 205 [175-255] & 0.57 \\
\hline Duration of OLV (min) & 192 [166-240] & $195[180-240]$ & $190[145-240]$ & 0.49 \\
\hline \multicolumn{5}{|l|}{ Comorbidities } \\
\hline Diabetes, n (\%) & $8(13)$ & $4(13)$ & $4(13)$ & 0.999 \\
\hline Hypertension, $\mathrm{n}(\%)$ & $35(50)$ & $10(33)$ & $16(53)$ & 0.192 \\
\hline Vascular disease, n (\%) & $20(33)$ & $10(33)$ & $10(33)$ & 0.999 \\
\hline COPD, n (\%) & $10(16)$ & $6(20)$ & $4(13)$ & 0.731 \\
\hline \multicolumn{5}{|l|}{ Preoperative spirometry } \\
\hline FVC (\% predicted) & 104 [93-117] & 99 [79-117] & 107 [96-118] & 0.204 \\
\hline FEV1 (\%) & 96 [79-109] & $90[70-105]$ & $105[86-116]$ & 0.061 \\
\hline FEV1/FVC & $75 \pm 12$ & $77 \pm 16$ & $74 \pm 9$ & 0.75 \\
\hline $\mathrm{KCO}(\%$ predicted $)$ & 74 [62-93] & $69[58-80]$ & 86 [67-98] & 0.086 \\
\hline ERV (\% predicted) & & & & \\
\hline
\end{tabular}

$B M I$ body mass index, $M R C$ Medical Research Council Scale, $M V$ mechanical ventilation, $O L V$ one lung ventilation, $V C$ vital capacity, $F E V I$ forced expiratory volume in the 1st second, $F V C$ forced vital capacity, $M E F$ maximal expiratory flow, $E R V$ expiratory reserve volume

$\mathrm{p}$ values are referred to comparison between PEEP $_{\text {INCREMENTAL }}$ and PEEP DECREMENTAL group
[37-58] \% to 33 [25-45]\% in the PEEP ${ }_{\text {DECREMENTAL }}$ group, (mean difference 22 [95\% CI 18-26]\%; p < 0.001 vs baseline). There was a reduction in shunt after intervention in $77 \%$ (23/30) of the patients in the PEEP INCREMENTAL versus $90 \%(27 / 30)$ in the PEEP ${ }_{\text {DECREMENTAL }}$ group $(\mathrm{p}=0.17$ for comparison among groups).

Low V/Q decreased from 86 [37-150] $\mathrm{mmHg}$ to 55 [38-75] $\mathrm{mmHg}$ in the PEEP INCREMENTAL $_{\text {group }(\mathrm{p}=0.14}$ vs baseline) and from 69 [23-144] $\mathrm{mmHg}$ to 57 [34-101] $\mathrm{mmHg}$ in the PEEP ${ }_{\text {DECREMENTAL }}$ group $(\mathrm{p}=0.58 \mathrm{vs}$ baseline).

High V/Q mismatch was similar among the two groups. (Table 2).

\subsection{Respiratory mechanics and gas exchange}

During the OLV pre-intervention (at ZEEP), the $\triangle \mathrm{P}$ did not differ between the two groups, with observations of 15

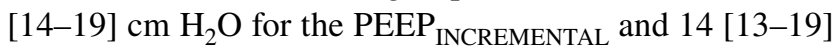

$\mathrm{cm} \mathrm{H}_{2} \mathrm{O}$ for the PEEP ${ }_{\text {DECREMENTAL }}$ group. The PEEP titration procedure resulted in a similar "optimal" median level in the two groups $\left(\mathrm{PEEP}_{\mathrm{INCREMENTAL}} 8\right.$ [6-12] $\mathrm{cm}$ $\mathrm{H}_{2} \mathrm{O}$, range 4-16 $\mathrm{cm} \mathrm{H} \mathrm{H}_{2} \mathrm{O}$; $\mathrm{PEEP}_{\text {DECREMENTAL }}$ : [8-10] cm $\mathrm{H}_{2} \mathrm{O}$, range 6-12 $\mathrm{cm} \mathrm{H}_{2} \mathrm{O} ; \mathrm{p}=0.74$ for comparison) (Table 2, Fig. 3). Nevertheless, the $\Delta \mathrm{P}$ was 10 [9-11] $\mathrm{cm}$

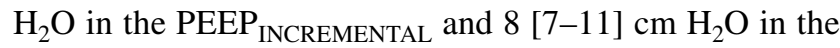
PEEP $_{\text {DECREMENTAL }}$ group $(\mathrm{p}=0.03$; Table 2$)$.

The energy load applied during the LRM in the PEEP $_{\text {DECREMENTAL }}$ group was 5.8 [4.7-7.1] J. The total energy load in the OLV post-intervention step was 1.175

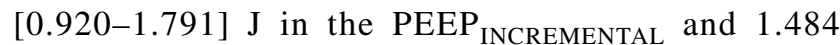

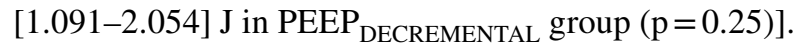

Only the patients in the PEEP DECREMENTAL group experienced a significant increase in the $\mathrm{PaO}_{2} / \mathrm{FIO}_{2}$ ratio after intervention (from 140 [99-176] to 186 [152-243], $\mathrm{p}<0.001)$. In the PEEP ${ }_{\text {DECREMENTAL }}$ group the $\mathrm{PaO}_{2} / \mathrm{FIO}_{2}$ ratio increased significantly after intervention. There were no significant changes in $\mathrm{PaCO}_{2}$ before or after intervention in both groups (Table 3). 
Table 2 Mechanical ventilation variables and V/Q measurement during the study period

\begin{tabular}{|c|c|c|c|c|c|c|c|c|}
\hline \multirow[t]{2}{*}{ Variable } & \multicolumn{2}{|c|}{ TLV, after induction } & \multicolumn{2}{|c|}{ OLV, prior to intervention } & \multicolumn{2}{|c|}{ OLV, after intervention } & \multicolumn{2}{|c|}{ TLV, End of surgery } \\
\hline & $\begin{array}{l}\text { PEEP- } \\
\text { INCREMENTAL }\end{array}$ & $\begin{array}{l}\text { PEEP- } \\
\text { DECREMENTAL }\end{array}$ & $\begin{array}{l}\text { PEEP- } \\
\text { INCREMENTAL }\end{array}$ & $\begin{array}{l}\text { PEEP- } \\
\text { DECREMENTAL }\end{array}$ & $\begin{array}{l}\text { PEEP- } \\
\text { INCREMENTAL }\end{array}$ & $\begin{array}{l}\text { PEEP- } \\
\text { DECREMENTAL }\end{array}$ & $\begin{array}{l}\text { PEEP- } \\
\text { INCREMENTAL }\end{array}$ & $\begin{array}{l}\text { PEEP- } \\
\text { DECREMENTAL }\end{array}$ \\
\hline \multicolumn{9}{|c|}{ Mechanical ventilation } \\
\hline $\begin{array}{c}\text { Paw }(\mathrm{cm} \\
\left.\mathrm{H}_{2} \mathrm{O}\right)\end{array}$ & $20[15-23]$ & 18 [14-20.5] & $\begin{array}{c}23[19.5- \\
27.5]\end{array}$ & $22[20-26]$ & $\begin{array}{l}25.5 \\
{[22.2-30]}\end{array}$ & 24 [23-29] & $\begin{array}{l}24.5[20.7- \\
28.2]\end{array}$ & 18 [14-20.5] \\
\hline $\begin{array}{l}\text { Plateau pres- } \\
\text { sure }(\mathrm{cm} \\
\left.\mathrm{H}_{2} \mathrm{O}\right)\end{array}$ & $13[10-15]$ & 13 [10-15] & 15 [14-19] & 15 [14-19] & 19 [17-22] & $17.5[15-21]$ & 19 [16-22] & 18 [15-20] \\
\hline $\begin{array}{l}\text { Driving } \\
\text { Pressure } \\
\left(\mathrm{cm} \mathrm{H}_{2} \mathrm{O}\right)\end{array}$ & $13[10-15]$ & $12[10-16]$ & 15 [14-19] & 14 [13-19] & $10[9-11]$ & $8[7-11]^{\# * *}$ & $10[8-12]$ & 9 [7-12] \\
\hline $\begin{array}{l}\text { PEEP }(\mathrm{cm} \\
\left.\mathrm{H}_{2} \mathrm{O}\right)\end{array}$ & 0 & 0 & 0 & 0 & $8[6-12]$ & $8[8-10]$ & $8[6-12]$ & $8[8-10]$ \\
\hline $\begin{array}{l}\text { Tidal vol- } \\
\text { ume }\end{array}$ & $\begin{array}{l}440[385- \\
500]\end{array}$ & $\begin{array}{l}440[400- \\
490]\end{array}$ & $\begin{array}{l}315[270- \\
350]\end{array}$ & $\begin{array}{l}310[290- \\
350]\end{array}$ & $\begin{array}{l}315[270- \\
350]\end{array}$ & $\begin{array}{l}310[290- \\
350]\end{array}$ & $\begin{array}{l}440[390- \\
500]\end{array}$ & 440 [400-490] \\
\hline $\begin{array}{l}\text { Respiratory } \\
\text { rate }\end{array}$ & 14 [14-15] & 14 [13-15] & 16 [14-16] & $16[14-16]$ & $\begin{array}{c}16[14.2- \\
17.5]\end{array}$ & 16 [16-18] & $16[14-16]$ & 16 [14-17] \\
\hline $\begin{array}{l}\text { Mechani- } \\
\text { cal power } \\
(\mathrm{J} / \mathrm{m})\end{array}$ & $\begin{array}{l}10.8 \\
{[8.6-12.4]}\end{array}$ & $9.5[8.1-12.7]$ & $5.6[4.5-6.8]$ & $5.8[4.4-6.6]$ & $6.8[5.4-8.8]^{*}$ & $7.0[5.9-8.6]^{*}$ & $\begin{array}{l}12.8[10.0- \\
16.1]\end{array}$ & $\begin{array}{l}13.3[11.4- \\
15.0]\end{array}$ \\
\hline \multicolumn{9}{|l|}{ V/Q variables } \\
\hline Shunt $(\%)$ & $\begin{array}{l}26.2[21.8- \\
32.9]\end{array}$ & $\begin{array}{l}24.0[16.1- \\
33.1]\end{array}$ & $\begin{array}{l}49.8[39.0- \\
55.0]\end{array}$ & $\begin{array}{l}45.2[37.5- \\
58.1]\end{array}$ & $\begin{array}{l}34.9[28.0- \\
42.1]^{*}\end{array}$ & $\begin{array}{l}33.1[24.7- \\
45.1]^{*}\end{array}$ & $\begin{array}{l}18.6 \\
{[9.0-25.2]}\end{array}$ & $18.5[9.8-22.6]$ \\
\hline $\begin{array}{l}\text { Low V/Q } \\
(\mathrm{mmHg})\end{array}$ & 39 [17-65] & $35[23-71]$ & $86[37-150]$ & 69 [23-144] & $55[38-75]$ & 57 [34-101] & $28[22-70]$ & 35 [24-72] \\
\hline $\begin{array}{l}\text { High V/Q } \\
(\mathrm{mmHg})\end{array}$ & $11[6-15]$ & $11[6-15]$ & $13[10-16]$ & $11[7-15]$ & 13 [11-18] & $13[6.7-17]$ & $12[10-16]$ & $12[7-17]$ \\
\hline
\end{tabular}

Paw Peak airway pressure, $P E E P$ positive end-expiratory pressure; $V / Q=$ Ventilation/perfusion ratio ${ }^{\#} \mathrm{p}<0.05$ vs the other group, ${ }^{*} \mathrm{p}<0.05$ vs prior to intervention

Fig. 2 Shunt evaluation during the study in the PEEP INCREMENTAL $_{\text {and }}$ PEEP $_{\text {DECREMENTAL }}$ group

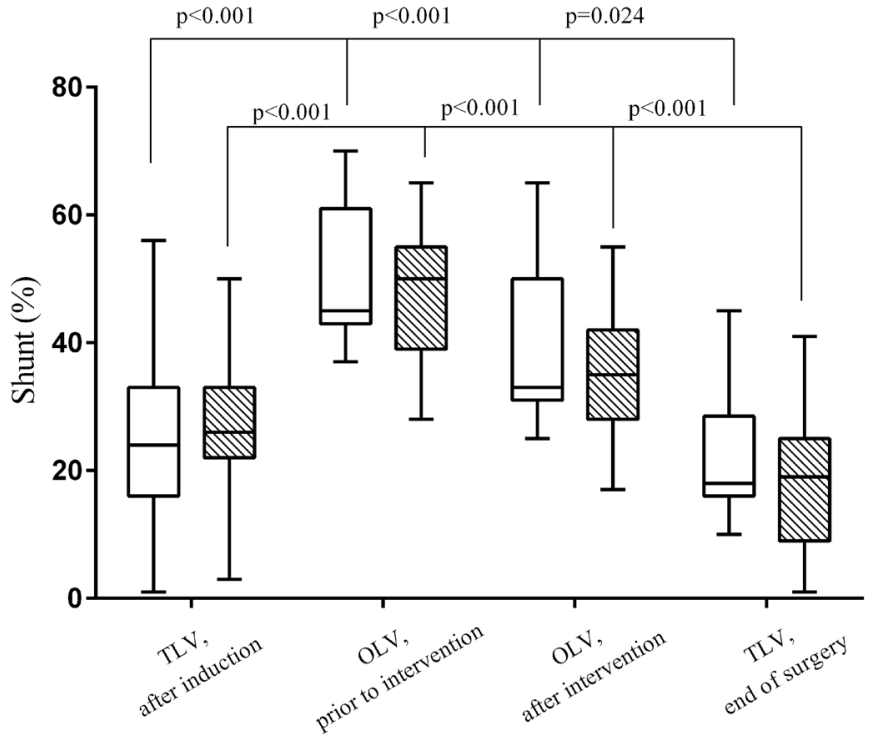

PEEP DECREMENTAL PEEPINCREMENTAL 


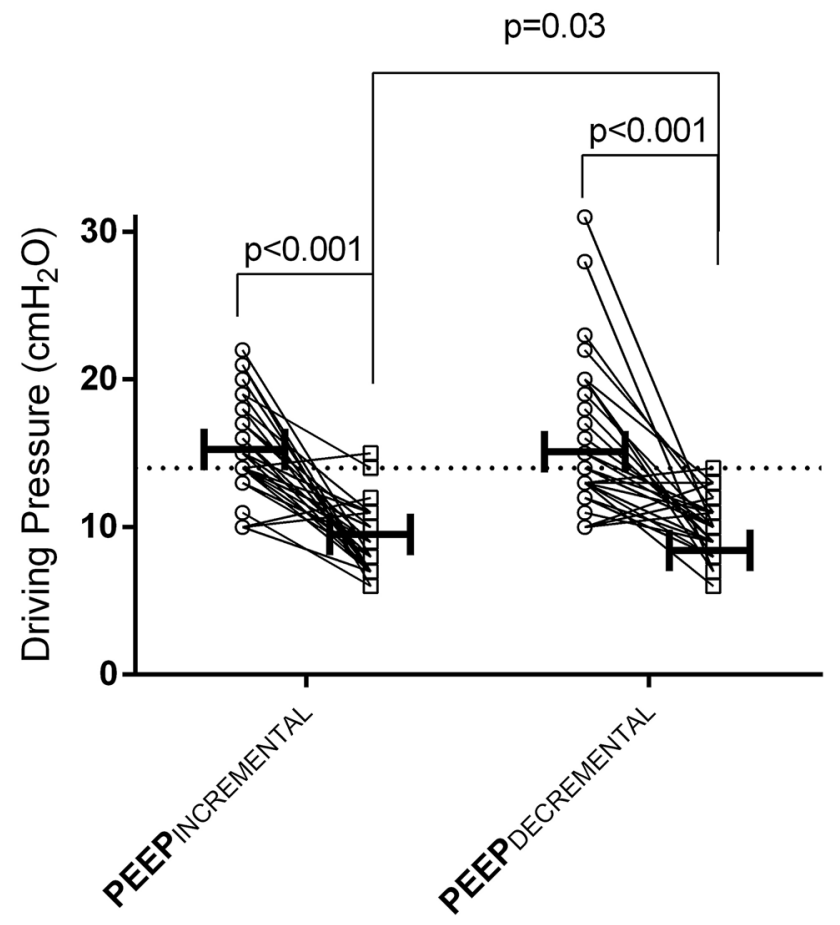

Fig. 3 Individual changes in driving pressure before and after the study intervention in the PEEP INCREMENTAL $_{\text {and PEEP }}$ DECREMENTAL group

\subsection{Perioperative assessment}

Intraoperative hemodynamic variables, as well as the number and kind of postoperative complications, are shown in Supplement Table 3. Patients in the two groups did not differ in terms of intraoperative management.

\subsection{Post-hoc subgroups analysis}

We performed various sub-group analyses to investigate whether different responses to the two PEEP titration strategies could be influenced by different clinical characteristics. No difference was found in PEEP INCREMENTAL or PEEP $_{\text {DECREMENTAL }}$ strategies when stratifying patients for age, BMI or history of COPD (Supplemental Fig. 2).

Among patients with $\Delta \mathrm{P}>14 \mathrm{~cm} \mathrm{H}_{2} \mathrm{O}$ prior to intervention $(\mathrm{n}=34)$, the reduction in $\Delta \mathrm{P}$ was more pronounced in

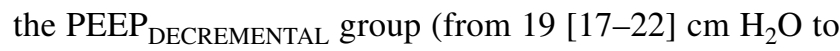
10 [8-11] $\mathrm{cm} \mathrm{H}_{2} \mathrm{O}$ ) than in the PEEP INCREMENTAL $_{\text {one (from }}$ 18 [15-20] $\mathrm{cm} \mathrm{H}_{2} \mathrm{O}$ to 10 [9-12] $\mathrm{cm} \mathrm{H}_{2} \mathrm{O}$ ), $\mathrm{p}=0.02$ for group comparison in favour of PEEP DECREMENTAL $_{\text {group). }}$

\section{Discussion}

The main result of our study is that, among patients undergoing video-assisted thoracic surgery in OLV, an open lung approach strategy based on low TV combined with a $\Delta \mathrm{P}$-oriented decremental PEEP titration resulted in lower values of driving pressure and increase in oxygenation when compared to a PEEP INCREMENTAL $_{\text {strategy. However, both }}$ strategies were equally able to reduce shunt and driving pressure at the end of surgery.

Individualized PEEP has been shown to improve regional ventilation distribution and oxygenation and to decrease the incidence of postoperative atelectasis and PPCs in both abdominal [23] and thoracic surgery [4]. On the other hand, high intraoperative driving pressure has been found to be an independent predictor of PPCs [5, 6]. Combining these concepts, a $\Delta \mathrm{P}$-oriented PEEP setting has been recently proposed for patient undergoing OLV during thoracic surgery.

Table 3 Blood gas analysis during the study period

\begin{tabular}{|c|c|c|c|c|c|c|c|c|}
\hline \multirow[t]{3}{*}{ Variable } & \multicolumn{2}{|c|}{ TLV, after induction } & \multicolumn{2}{|c|}{ OLV, prior to intervention } & \multicolumn{2}{|c|}{ OLV, after intervention } & \multicolumn{2}{|c|}{ TLV, End of surgery } \\
\hline & PEEP- & PEEP- & PEEP- & PEEP- & PEEP- & PEEP- & PEEP- & PEEP- \\
\hline & INCREMENTAL & DECREMENTAL & INCREMENTAL & DECREMENTAL & INCREMENTAL & DECREMENTAL & INCREMENTAL & DECREMENTAL \\
\hline $\begin{array}{l}\mathrm{PaO}_{2} / \mathrm{F}_{\mathrm{I}} \mathrm{O}_{2} \\
\text { ratio } \\
(\mathrm{mmHg})\end{array}$ & $\begin{array}{c}350[238- \\
438]\end{array}$ & $\begin{array}{c}298 \text { [219- } \\
447]\end{array}$ & $\begin{array}{c}139[103- \\
202]\end{array}$ & 140 [99-176] & $\begin{array}{c}153[103- \\
192]\end{array}$ & $\begin{array}{c}186[152- \\
243] \# *\end{array}$ & $\begin{array}{c}423[241- \\
492]\end{array}$ & $402[262-463]$ \\
\hline $\mathrm{F}_{\mathrm{I}} \mathrm{O}_{2}$ & $50[40-55]$ & $40[40-50]$ & 58 [49-66] & $55[49-60]$ & $65[56-73]^{*}$ & $50[40-52]^{\# *}$ & $57[50-65]$ & $50[44-60]$ \\
\hline $\begin{array}{l}\mathrm{PaCO}_{2} \\
\quad(\mathrm{mmHg})\end{array}$ & $47[42-51]$ & $38[42-52]$ & $55[50-59]$ & 53 [49-60] & $59[54-62]$ & $54[51-64]$ & $49[45-52]$ & $50[43-53]$ \\
\hline $\mathrm{pH}$ & $7.36 \pm 0.05$ & $7.36 \pm 0.05$ & $7.31 \pm 0.05$ & $7.31 \pm 0.07$ & $7.27 \pm 0.05^{*}$ & $7.28 \pm 0.06^{*}$ & $7.31 \pm 0.04$ & $7.31 \pm 0.06$ \\
\hline $\mathrm{HCO}_{3}^{-}$ & $26.9 \pm 2.6$ & $26.5 \pm 2.5$ & $27.0 \pm 1.8$ & $26.7 \pm 2.3$ & $26.4 \pm 1.7$ & $26.3 \pm 2.5$ & $24.7 \pm 1.9$ & $24.4 \pm 2.3$ \\
\hline $\begin{array}{l}\text { Lactate } \\
\qquad(\mathrm{mmol} / \mathrm{L})\end{array}$ & $1[0.7-1.2]$ & $0.8[0.7-1.2]$ & $0.8[0.7-1.2]$ & $0.8[0.7-1.1]$ & $0.8[0.6-1]$ & $0.8[0.7-1.1]$ & $0.9[0.7-1.0]$ & $0.8[0.7-1.0]$ \\
\hline $\mathrm{Hb}(\mathrm{g} / \mathrm{dL})$ & $12.6 \pm 1.8$ & $12.4 \pm 1.6$ & $12.1 \pm 1.6$ & $12.0 \pm 1.6$ & $12.1 \pm 1.7$ & $11.9 \pm 1.6$ & $12.0 \pm 1.9$ & $11.5 \pm 1.7$ \\
\hline
\end{tabular}

$\mathrm{Pa}_{\mathrm{CO} 2}$ arterial partial pressure of carbon dioxide, $\mathrm{Pa}_{\mathrm{O} 2}$ arterial partial pressure of oxygen, $\mathrm{F}_{\mathrm{I}} \mathrm{O}_{2}$ fraction of inspired oxygen, $\mathrm{Hb}$ hemoglobin ${ }^{\#} \mathrm{p}<0.05$ vs the other group, ${ }^{*} \mathrm{p}<0.05$ vs prior to intervention 
However, there are at least two different approaches to PEEP setting in this context: the incremental or the decremental approach. We found that both approaches were able to reduce $\Delta \mathrm{P}$ to "safe" levels $[6,21,24]$, and that, surprisingly the PEEP levels needed to minimize the $\triangle \mathrm{P}$ were similar in both groups (Table 2). However, the PEEP DECREMENTAL $_{\text {strategy }}$ resulted in the lowest intraoperative $\Delta \mathrm{P}$. These results gain clinical relevance due to the described relationship between intraoperative $\Delta \mathrm{P}$ and postoperative outcomes [5, 6]. Our data confirm the results of recent studies on the effects of the open lung approach applied during OLV [8]. Rauseo and coworkers found that a PEEP ${ }_{\text {DECREMENTAL }}$ strategy was able to decrease transpulmonary driving pressure and to improve oxygenation [8] and Ferrando and co-workers showed that a PEEP $_{\text {DECREMENTAL }}$ was able to preserve the improvement in static compliance obtained through a LRM [7]. This could explain our findings of a lower $\Delta \mathrm{P}$ and of an improvement in oxygenation in the PEEP ${ }_{\text {DECREMENTAL }}$ group. We hope that our physiological data could help to interpret the results of the clinical studies on PEEP setting during OLV. Indeed, in our study we reproduced the protocols of two recent randomized controlled trials, the Park study [4] and the ongoing PROTHOR trial [12].

One major concern is that the PEEP DeCREMENTAL $_{\text {. }}$ approach could critically decrease patient's cardiac output through both a preload and an afterload effect of the LRM needed to recruit the lungs before PEEP titration. However, the hemodynamic impact of the LRM during OLV has been previously shown to be mostly negligible $[7,8,25,26]$. Some authors advocated the risk that the high amount of energy delivered to the lungs could result in alveolar hyperinflation and thus in a sort of unconscious "harmful" strategy $[27,28]$. Nonetheless, in our patients we found that the mechanical power applied during the LRM was 5.8 [4.7-7.1] $\mathrm{J}$, considerably lower than the "harmful" threshold of $25 \mathrm{~J} /$ min Joules suggested in patients with ARDS [29]. Additionally, the high V/Q fraction, a suitable surrogate of hyperinflation, was similar between the two groups (Table 2),

We also assessed the differential effects of the two strategies on the cohort of patients with higher baseline $\Delta \mathrm{P}$ (i.e. higher than $14 \mathrm{~cm}_{2} \mathrm{O}$ ) during OLV. This subgroup analysis showed that these patients had a greater decrease in $\Delta \mathrm{P}$ and increase in $\mathrm{PaO}_{2} / \mathrm{FIO}_{2}$ ratio when randomized to the PEEP DECREMENTAL $_{\text {group as compared to }}$ the PEEP INCREMENTAL $_{\text {one. Thus, despite our data should }}$ be extrapolated to the clinical context with caution, we speculate that patients with more compromised oxygenation and lung mechanics could be the best candidate to the PEEP $_{\text {DECREMENTAL }}$ strategy.

Our study has some limitations. First of all, our results could have been influenced by the effects of the LRM, which was performed only in the PEEP DECREMENTAL $_{\text {group. How- }}$ ever, we would like to point out that the LRM is part of the open lung approach [30] and thus it is impossible to differentiate the role of PEEP and LRM in our PEEP DECREMENTAL group. On the other hand, since we were interested in reproducing the PEEP INCREMENTAL $_{\text {strategy proposed in the }}$ Park's clinical trial [4], we did not apply any LRM in the PEEP $_{\text {INCREMENTAL }}$ group. Secondly, our study was not powered to investigate clinical outcomes of such PPCs. Thirdly, we did not record advanced hemodynamic parameters and, thus, we cannot report on the differential impact of the two strategies. However, previous studies have shown that both PEEP and LRM have slight and transient effects on cardiac output during OLV [25, 26]. Lastly, we used the $\mathrm{PaO}_{2} / \mathrm{FIO}_{2}$ ratio as index of oxygenation but applied a fixed $\mathrm{FIO}_{2}$ in the two groups, and this could have partially influenced our results [20].

In conclusion, we have shown the beneficial physiological effects of two $\triangle \mathrm{P}$-oriented PEEP titration strategies during OLV. According to our data, as compared with an incremental PEEP titration approach, decremental PEEP titration immediately after a LRM was more effective in decreasing $\Delta \mathrm{P}$ and improving oxygenation, particularly in patients with higher (i.e. $>$ than $14 \mathrm{~cm} \mathrm{H}_{2} \mathrm{O}$ ) intraoperative $\Delta \mathrm{P}$.

Author contributions SS: This author helped to the design of the study, analyzed the data and wrote the paper. GS: This author helped to the design of the study, analyzed the data and wrote the paper. KDS: This author helped to revise and wrote the paper. SG: This author helped to collected the data. CG: This author helped to revise and wrote the paper. MP: This author helped to collect data and revise the paper. MF: This author helped to revise the paper. RDM: This author helped to revise the paper. RR: This author helped to collect data and revise the paper. RSE: This author helped to revise and wrote the paper. VCA: This author helped to the design of the study, analyzed the data and wrote the paper.

Funding Support was provided solely from institutional and/or departmental sources.

\section{Compliance with ethical standards}

Conflict of interest None of the authors received compensation to perform this study. Dr. Rees is a board member and minor shareholder of Mermaid Care A/S (Nørresundby, Denmark), who commercially produces the ALPE system. Dr. Karbing has performed consultancy work for Mermaid Care A/S. The remaining authors declare no competing interests.

Ethical approval The trial was approved by the Ethics Committee of our institution (protocol No. 11072017).

Informed consent Informed consent was obtained from each patient before surgery. 


\section{References}

1. Spadaro S, Karbing DS, Mauri T, et al. Effect of positive endexpiratory pressure on pulmonary shunt and dynamic compliance during abdominal surgery. Br J Anaesth. 2016;116(6):855-61.

2. Spadaro S, Grasso S, Karbing DS, et al. Physiologic evaluation of ventilation perfusion mismatch and respiratory mechanics at different positive end-expiratory pressure in patients undergoing protective one-lung ventilation. Anesthesiology. 2018;128(3):531-8.

3. Young CC, Harris EM, Vacchiano C, et al. Lung-protective ventilation for the surgical patient: international expert panel-based consensus recommendations. Br J Anaesth. 2019;123(6):898-913.

4. Park M, Ahn HJ, Kim JA, et al. Driving pressure during thoracic surgery: a randomized clinical trial. Anesthesiology. 2019;130(3):385-93.

5. Blank RS, Colquhoun DA, Durieux ME, et al. Management of one-lung ventilation: impact of tidal volume on complications after thoracic surgery. Anesthesiology. 2016;124(6):1286-95.

6. Neto AS, Hemmes SN, Barbas CS, et al. Association between driving pressure and development of postoperative pulmonary complications in patients undergoing mechanical ventilation for general anaesthesia: a meta-analysis of individual patient data. Lancet Respir Med. 2016;4(4):272-80.

7. Ferrando C, Mugarra A, Gutierrez A, et al. Setting individualized positive end-expiratory pressure level with a positive endexpiratory pressure decrement trial after a recruitment maneuver improves oxygenation and lung mechanics during one-lung ventilation. Anesth Analg. 2014;118(3):657-65.

8. Rauseo M, Mirabella L, Grasso S, et al. Peep titration based on the open lung approach during one lung ventilation in thoracic surgery: a physiological study. BMC Anesthesiol. 2018;18(1):156.

9. Girgis K, Hamed H, Khater Y, Kacmarek RA. decremental PEEP trial identifies the PEEP level that maintains oxygenation after lung recruitment. Respir Care. 2006;51(10):1132-9.

10. Gernoth C, Wagner G, Pelosi P, Luecke T. Respiratory and haemodynamic changes during decremental open lung positive end-expiratory pressure titration in patients with acute respiratory distress syndrome. Crit Care. 2009;13(2):R59.

11. Batchelor TJP, Rasburn NJ, Abdelnour-Berchtold E, et al. Guidelines for enhanced recovery after lung surgery: recommendations of the Enhanced Recovery After Surgery (ERAS®). Soc Eur Soc Thorac Surg (ESTS). 2019;55(1):91-115.

12. Kiss T, Wittenstein J, Becker C, et al. Protective ventilation with high versus low positive end-expiratory pressure during one-lung ventilation for thoracic surgery (PROTHOR): study protocol for a randomized controlled trial. Trials. 2019;20(1):213.

13. Villagra A, Ochagavia A, Vatua S, et al. Recruitment maneuvers during lung protective ventilation in acute respiratory distress syndrome. Am J Respir Crit Care Med. 2002;165:165-70.

14. Gattinoni L, Tonetti T, Cressoni M, et al. Ventilator-related causes of lung injury: the mechanical power. Intensive Care Med. 2016;42(10):1567-75.

15. Spadaro S, Caramori G, Rizzuto C, et al. Expiratory flow limitation as a risk factor for pulmonary complications after major abdominal surgery. Anesth Analg. 2017;124(2):524-30.
16. Rees SE, Kjærgaard S, Thorgaard P, Malczynski J, Toft E, Andreassen S. The Automatic Lung Parameter Estimator (ALPE) system: non-invasive estimation of pulmonary gas exchange parameters in 10-15 minutes. J Clin Monit Comput. 2002;17:43-52.

17. Karbing DS, Kjærgaard S, Andreassen S, Espersen K, Rees SE. Minimal model quantification of pulmonary gas exchange in intensive care patients. Med Eng Phys. 2011;33:240-8.

18. Kjaergaard S, Rees S, Malczynski J, Nielsen JA, Thorgaard P, Toft E, Andreassen S. Non-invasive estimation of shunt and ventilation-perfusion mismatch. Intensive Care Med. 2003;29(5):727-34.

19. Kjaergaard S, Rees SE, Grønlund J, et al. Hypoxaemia after cardiac surgery: clinical application of a model of pulmonary gas exchange. Eur J Anaesthesiol. 2004;21(4):296-301.

20. Karbing DS, Kjaergaard S, Smith BW, et al. Variation in the $\mathrm{PaO}_{2} /$ $\mathrm{FIO}_{2}$ ratio with $\mathrm{FIO}_{2}$ : mathematical and experimental description, and clinical relevance. Crit Care. 2007;11(6):R118.

21. Bellani G, Laffey JG, Pham T, et al. Epidemiology, patterns of care, and mortality for patients with acute respiratory distress syndrome in Intensive Care Units in 50 countries. JAMA. 2016;315(8):788-800.

22. Tusman G, Böhm SH, Sipmann FS, Maisch S. Lung recruitment improves the efficiency of ventilation and gas exchange during one-lung ventilation anesthesia. Anesth Analg. 2004;98(6):1604-9.

23. Pereira SM, Tucci MR, Morais CCA, et al. Individual positive end-expiratory pressure settings optimize intraoperative mechanical ventilation and reduce postoperative atelectasis. Anesthesiology. 2018;129(6):1070-81.

24. Amato MB, Meade MO, Slutsky AS, et al. Driving pressure and survival in the acute respiratory distress syndrome. N Engl J Med. 2015;372(8):747-55.

25. Cinnella G, Grasso S, Natale C, et al. Physiological effects of a lung-recruiting strategy applied during one-lung ventilation. Acta Anaesthesiol Scand. 2008;52:766-75.

26. Garutti I, Martinez G, Cruz P, Piñeiro P, Olmedilla L, de la Gala $F$. The impact of lung recruitment on hemodynamics during onelung ventilation. J Cardiothorac Vasc Anesth. 2009;23(4):506-8.

27. Cipulli F, Vasques F, Duscio E, Romitti F, Quintel M, Gattinoni L. Atelectrauma or volutrauma: the dilemma. J Thorac Dis. 2018;10(3):1258-64.

28. Kidane B, Choi S, Fortin D, et al. Use of lung-protective strategies during one-lung ventilation surgery: a multi-institutional survey. Ann Transl Med. 2018;6(13):269.

29. Cressoni M, Gotti M, Chiurazzi C, et al. Mechanical power and development of ventilator-induced lung injury. Anesthesiology. 2016;124(5):1100-8.

30. Carramiñana A, Ferrando C, Unzueta M, et al. Rationale and study design for an individualized perioperative open lung ventilatory strategy in patients on one-lung ventilation (iPROVE-OLV). J Cardiothorac Vasc Anesth. 2019;33(9):2492-502.

Publisher's Note Springer Nature remains neutral with regard to jurisdictional claims in published maps and institutional affiliations. 